\title{
DEVELOPMENT OF SUSTAINED RELEASE TABLETS CONTAINING SOLID DISPERSIONS OF BACLOFEN
}

\author{
K. H. Janardhana ${ }^{1}$, R. Deveswaran ${ }^{1 *}$, S. Bharath ${ }^{1}$, B.V. Basavaraj ${ }^{1}$, V. Madhavan ${ }^{2}$ \\ ${ }^{1}$ Department of Pharmaceutics, M.S.Ramaiah College of Pharmacy, MSRIT Post, Bangalore-54. \\ ${ }^{2}$ Department of Pharmacognosy, M.S.Ramaiah College of Pharmacy, MSRIT Post, Bangalore-54.
}

Received: 18 April 2013 / Accepted: 07 December 2013 / Published online: 31 December 2013

\begin{abstract}
Sustained release tablets containing solid dispersions granules of a poorly water soluble drug were prepared to investigate the controlled release of the drug. Baclofen was chosen because of its poor water solubility and short elimination half-life. Poloxamer 188 and PEG 6000 were used as solid dispersion carrier. Free flowing solid dispersion granules were prepared by adsorbing the melt of the drug and carriers onto the surface of an adsorbent, Carbopol 934P followed by direct compression with HPMC K4M and HPMC K100 to obtain an solid dispersion loaded sustained release tablets. FTIR studies confirmed that the compatibility of drug and carriers. Differential scanning calorimetry (DSC) and X-ray diffraction (XRD) revealed partially amorphous structures of the drug in solid dispersion granules. The solid dispersion granules dissolved completely within 30 min, which was much faster than that of pure drug baclofen. The sustained release of baclofen from the solid dispersion containing tablet was achieved for $2 \mathrm{~h}$ in gastric fluid $(\mathrm{pH}$ 1.2) and for up to $10 \mathrm{~h}$ in intestinal fluid ( $\mathrm{pH}$ 6.8). A combination of solid dispersion techniques using adsorption and sustained release concepts is a promising approach to control the release rate of poorly watersoluble drugs.
\end{abstract}

Key words: Solid dispersion; baclofen; sustained release; adsorbent.

Author Correspondence, e-mail: devs_mdu@yahoo.com

ICID: 1079080 


\section{INTRODUCTION}

One of the most promising methods of promoting the dissolution of poorly water-soluble drugs is the delivery of a solid dispersion via an efficient carrier. Polyethylene glycol, poloxamer are most widely used solid dispersion carriers because of their strong hydrophilic properties and ability to form molecular adducts with many compounds ${ }^{1}$. Sustained release (SR) systems are known to maintain therapeutically effective concentrations of drugs with short elimination half-lives in circulation over an extended period. The SR dosage forms that release drugs $\mathrm{pH}$ independently in the gastrointestinal tract are preferred to avoid numerous biopharmaceutical variables and to reduce intra and inter individual variations in bioavailability. Moreover, SR dosage forms containing poorly water-soluble drugs require both solubilization and release-modulation for therapeutic efficacy ${ }^{2,3}$. Solid dispersion technology is the science of dispersing one or more active ingredients in an inert matrix in the solid stage in order to achieve increased dissolution rate, sustained release of drugs, altered solid state properties, enhanced release of drugs from ointment and suppository bases, and improved solubility and stability ${ }^{4}$. Sustained release dosage forms containing solid dispersion granules (SD-SR) are an attractive pharmaceutical approach to improve the dissolution rate of poorly water-soluble drugs and drugs with short elimination half life ${ }^{5}$.

Baclofen is an oral and injectable medication that relaxes skeletal muscles, the muscles that move the skeleton (and also called striated muscle) ${ }^{6}$. Chemically, baclofen is related to gammaaminobutyric acid (GABA), a naturally-occurring neurotransmitter in the brain. Neurotransmitters are chemicals that nerves use to communicate with one another. GABA released by some nerves causes the activity of other nerves to decrease. Baclofen blocks the activity of nerves within the part of the brain that controls the contraction and relaxation of skeletal muscle. It is used for treating spasm of skeletal muscles, muscle clonus, rigidity, and pain caused by disorders such as multiple sclerosis $^{7,8}$. It is also injected into the spinal cord (intrathecal) for management of severe spasticity. The present study was aimed to prepare free-flowing SD granules using polymers like PEG 6000, Poloxamer 188 along with an adsorbent and then obtain a SD-SR tablet for release of a poorly water-soluble drug. The SDSR tablet was prepared via direct compression of SD granules. 


\section{MATERIALS AND METHODS}

\subsection{Materials}

Baclofen was purchased from Medilux laboratories Pvt. Ltd, New Delhi. Carbopol 934, PEG 6000, Poloxamer 188, Potassium Dihydrogen Phosphate, Sodium Hydroxide Pellets, HPMC K 4 M was obtained from Yarrow Chem Products, Mumbai. Calcium phosphate dibasic was obtained from Himedia laboratories Pvt. Ltd, Mumbai. HPMC K 100 was obtained from Rolex Laboratory, Mumbai. Hydrochloric Acid was obtained from RFCL Limited, New Delhi. All other chemicals used were of analytical grade.

\subsection{Preparation of SD granules}

The solid dispersion granules were prepared by hot melt method. In this study poloxamer 188 was used as a carrier and carbopol 934 was used as an adsorbent. Poloxamer 188 was melted in a beaker using a water bath and baclofen was added slowly with stirring to obtain a homogenous mixture. Carbopol 934 was added gradually to the molten mixture with continuous stirring. The dispersion was cooled in deep freezer at $-20^{\circ} \mathrm{C}$ which was followed by passing through a sieve $400 \mu \mathrm{m}$ in diameter. The weight ratio of drug and carrier were between $1: 1$ to $1: 2$, whereas the ratio of drug and adsorbent was between 1:0.5 to 1:1. A physical mixture was obtained by mixing drug, carrier and adsorbent by using spatula.

\subsection{Fourier Transform Infrared spectroscopic studies}

The FTIR spectra of pure baclofen, carbapo1934, poloxamer 188, PEG 6000, solid dispersion products, physical mixture of polymers and drug were studied. A small amount of drug was mixed with the spectroscopic grade of $\mathrm{KBr}$ and triturated for uniform mixing. The prepared mixture is filled in a palate and was exposed to the IR beam and spectra were recorded in the range of 400$4000 \mathrm{~cm}^{-1}$ by using FTIR spectrophotometer (FTIR 8400 Shimadzu, Japan).

\subsection{Differential scanning calorimetric analysis}

$2 \mathrm{mg}$ of sample was placed in a $50 \mu \mathrm{L}$ perforated aluminium pan and sealed. Heat runs for each sample were set from $5^{\circ} \mathrm{C}$ to $300^{\circ} \mathrm{C}$ using nitrogen as purging gas and the samples were analyzed. Thermograms of the samples (Baclofen, Poloxamer 188, PEG 6000, Carbopol 934, solid dispersion product of baclofen with poloxamer 188 and solid dispersion product of baclofen with PEG 6000) were recorded.

\subsection{X-Ray Diffraction Analysis}


The powder X-RD patterns of drug, $\beta$-Cyclodextrin, and complexes were recorded by using Philips Holland -PW 1710 scanner with filter $\mathrm{Cu}$ radiation over the interval 5-60\% 20 . The operation data were as follows: voltage $35 \mathrm{kV}$, current $20 \mathrm{~mA}$, filter $\mathrm{Cu}$ and scanning speed $1 \% \mathrm{~min}$.

\subsection{Micromeritic properties of SD granules}

Carr's compressibility index, Bulk density, Angle of repose and Hausner's ratio were determined as per Indian Pharmacopoeia ${ }^{9}$.

\subsection{Tablet preparation containing SD granules}

Sustained release tablets containing solid dispersions of baclofen equivalent to $50 \mathrm{mg}$ was prepared via direct compression. Solid dispersion granules were mixed with varying amounts of HPMC K4M and HPMC K100 as sustaining agent. Dicalcium phosphate is used as tableting agent, and magnesium stearate as a lubricant. A homogenous blend was passed through a $250 \mu \mathrm{m}$ sieve and then directly compressed into tablets using $8 \mathrm{~mm}$ punch in a single rotary tablet press (Rimek RSB4 minipress, Cadmach). The formula for the tablets are shown in table 1. 
Table 1. Formulation of Baclofen sustained release tablets containing solid dispersion granules

* Amount of baclofen in solid dispersion is $50 \mathrm{mg}$

Pre and Post compression parameters

\begin{tabular}{|c|c|c|c|c|c|c|c|c|c|c|c|c|c|}
\hline \multirow[b]{3}{*}{ S.No } & \multirow[b]{3}{*}{ Ingredients } & \multicolumn{12}{|c|}{ Formulation code (Quantity in $\mathrm{mg}$ ) } \\
\hline & & \multicolumn{6}{|c|}{ Solid Dispersion with polaxomer-188 } & \multicolumn{6}{|c|}{ Solid Dispersion with PEG-6000 } \\
\hline & & $\mathrm{A}_{1} \mathrm{~F}$ & $\mathrm{~A}_{1} \mathrm{~F}$ & $\mathrm{~A}_{1} \mathrm{~F}$ & $\mathrm{~A}_{2} \mathrm{~F}_{1}$ & $\overline{\mathrm{A}_{2} \mathrm{~F}_{2}}$ & $\mathrm{~A}_{2} \mathrm{~F}$ & $\mathrm{~B}_{1} \mathrm{~F}_{1}$ & $\mathrm{~B}_{1} \mathrm{~F}_{2}$ & $\mathrm{~B}_{1} \mathrm{~F}_{3}$ & $\mathrm{~B}_{2} \mathrm{~F}_{1}$ & $\mathrm{~B}_{2} \mathrm{~F}_{2}$ & $\mathrm{~B}_{2} \mathrm{~F}_{3}$ \\
\hline 1 & $\begin{array}{l}\text { Solid } \\
\text { dispersion } \\
\text { of } \\
\text { baclofen* } \\
(\mathrm{mg})\end{array}$ & 150 & 150 & 150 & 150 & 150 & 150 & 150 & 150 & 150 & 150 & 150 & 150 \\
\hline 2 & $\begin{array}{l}\text { Magnesium } \\
\text { stearate } \\
(\mathrm{mg})\end{array}$ & 5 & 5 & 5 & 5 & 5 & 5 & 5 & 5 & 5 & 5 & 5 & 5 \\
\hline 3 & $\begin{array}{l}\text { HPMC } \\
\text { K4M (mg) }\end{array}$ & 30 & 60 & 90 & -- & -- & -- & 30 & 60 & 90 & -- & -- & -- \\
\hline 4 & $\begin{array}{l}\text { HPMC K- } \\
100(\mathrm{mg})\end{array}$ & -- & -- & -- & 30 & 60 & 90 & -- & -- & -- & 30 & 60 & 90 \\
\hline 5 & $\begin{array}{l}\text { Dicalcium } \\
\text { phosphate } \\
\text { (mg) }\end{array}$ & 115 & 85 & 55 & 115 & 85 & 55 & 115 & 85 & 55 & 115 & 85 & 55 \\
\hline \multicolumn{2}{|c|}{$\begin{array}{l}\text { Total tablet weight } \\
\text { (mg) }\end{array}$} & 300 & 300 & 300 & 300 & 300 & 300 & 300 & 300 & 300 & 300 & 300 & 300 \\
\hline
\end{tabular}

Pre compression parameters such as bulk density, tap density, Hausner's ratio and Carr's index were determined; Post compression parameters such as weight variation test, hardness, thickness and friability were calculated.

\subsection{Drug content estimation}

Ten tablets of each formulation were weighed, triturated and powdered. Powder triturate equivalent to average weight of tablet was weighed and transferred to $50 \mathrm{ml}$ volumetric flask, Initially about $25 \mathrm{ml}$ of $0.1 \mathrm{~N} \mathrm{HCl}$ was added and the flask was shaken thoroughly and the volume was made up to $50 \mathrm{ml}$ with $0.1 \mathrm{~N} \mathrm{HCl}$. From the resulting solution $5 \mathrm{ml}$ was pipetted, diluted to $100 \mathrm{ml}$ with $0.1 \mathrm{~N}$ $\mathrm{HCl}$. From the above solution, $3 \mathrm{ml}$ was pipetted, diluted to $25 \mathrm{ml}$ with $0.1 \mathrm{~N} \mathrm{HCl}$ and drug content was estimated at $220 \mathrm{~nm}$ using UV spectrophotometer against $0.1 \mathrm{~N} \mathrm{HCl}$ as blank ${ }^{10}$.

\subsection{In-vitro drug release studies}


Drug release studies were carried out using USP XXIII dissolution test apparatus, rotating paddle method (Lab India, Mumbai, India). The study was conducted at $37 \pm 0.5^{\circ} \mathrm{C}$ and $50 \mathrm{rpm}$ using 900 $\mathrm{ml}$ of $1.2 \mathrm{pH}$ buffer for $2 \mathrm{hr}$. followed by $6.8 \mathrm{pH}$ buffer until completion of the studies. Samples $(2 \mathrm{ml})$ were withdrawn from the dissolution apparatus at regular pre-determined time intervals and fresh medium was replaced in order to maintain sink condition. The withdrawn samples were diluted suitably and drug content was measured spectrophotometrically at 220nm, using $0.1 \mathrm{~N} \mathrm{Hcl}$ as blank and percentage drug release was calculated from the standard calibration curve.

\subsection{In-vitro drug release mechanism}

The dissolution data of all formulations were fitted to zero-order, first-order, Hixson-Crowell, Higuchi and Korsemeyer and Peppas models to predict the drug release mechanism ${ }^{11}$.

\subsection{Stability study}

Based on the ICH guidelines ${ }^{12}$, the stability studies were carried out in an environmental chamber (Dempo Instruments, India). The optimized microspheres formulation were stored at $25 \pm 2^{\circ} \mathrm{C}$ and $60 \% \pm 5 \% \mathrm{RH}$ for a period of 12 months and at $40 \pm 2^{\circ} \mathrm{C}$ and $75 \% \pm 5 \% \mathrm{RH}$ for a period of 6 months. At intervals of 0,2, 4 and 6 months for accelerated storage condition and at 3 month interval during 12 months, for long-term storage condition, the samples were tested for changes in physical appearance and drug content.

\section{RESULTS AND DISCUSSION}

The solid dispersions of baclofen were prepared by hot melt method with varying concentrations of carriers such as PEG 6000, Poloxamer 188 and Carbopol 934 as adsorbent. Baclofen sustained release tablets containing solid dispersion granules were prepared by direct compression method. In the present study 12 formulations with varying concentrations of HPMC K4M and HPMC $\mathrm{K} 100 \mathrm{M}$ as sustaining agents were prepared; each tablet weighing $300 \mathrm{mg}$ and containing $50 \mathrm{mg}$ of baclofen. Baclofen was found to be linear in the range of $2-12 \mu \mathrm{g} / \mathrm{ml}$ with a regression value of 0.9973 in $0.1 \mathrm{~N} \mathrm{HCl}$ and thus considered as the Beer's range. The calculations of in-vitro drug release, drug content and stability studies are based on the calibration curve. The melting point of baclofen was determined by capillary method and was found to be $208^{\circ} \mathrm{C}$. It complies with IP standards thus indicating the purity of the drug sample. 


\subsection{FTIR studies}

The IR spectrum of pure drug, carrier, adsorbent and physical mixture of drug and carriers were studied. FTIR technique has been used here to study the physical and chemical interaction between drug and excipients used. The IR spectra of baclofen showed the characteristic absorption bands for $\mathrm{C}-\mathrm{Cl}$ stretch at $831.26 \mathrm{~cm}^{-1}, \mathrm{C}-\mathrm{O}$ stretch at $1244.00 \mathrm{~cm}^{-1}, \mathrm{O}-\mathrm{H}$ bending at $1394.44 \mathrm{~cm}^{-1}$, aromatic $\mathrm{C}-\mathrm{C}$ strech at $1515.94 \mathrm{~cm}^{-1}$ and aromatic $\mathrm{C}-\mathrm{H}$ stretch at $3049.25 \mathrm{~cm}^{-1}$ figure-1a. The IR spectra of carbopol 934P showed the characteristic absorption bands for $\mathrm{C}=\mathrm{O}$ carboxylate stretch at 1728.10 $\mathrm{cm}^{-1}, \mathrm{C}-\mathrm{H}$ alkane stretch at $2929.67 \mathrm{~cm}^{-1}, \mathrm{C}-\mathrm{O}$ stretch at $1224.71 \mathrm{~cm}^{-1}, \mathrm{O}-\mathrm{H}$ stretch at $3280.69 \mathrm{~cm}^{-}$ ${ }^{1}$ figure-1b. The IR spectra of PEG 6000 demonstrated the characteristic absorption bands for $\mathrm{O}-\mathrm{H}$ stretch at $3600.85 \mathrm{~cm}^{-1}, \mathrm{C}-\mathrm{H}$ alkane stretch at $2935.46 \mathrm{~cm}^{-1}$, C-O-C ether stretch at $1139.85 \mathrm{~cm}^{-1}$ figure-1c. The IR spectra of poloxamer 188 demonstrated the characteristic absorption bands for $\mathrm{O}-\mathrm{H}$ stretch at $3637.50 \mathrm{~cm}^{-1}, \mathrm{C}-\mathrm{H}$ alkane stretch at $2873.74 \mathrm{~cm}^{-1}, \mathrm{C}-\mathrm{O}-\mathrm{C}$ ether stretch at 1137.92 $\mathrm{cm}^{-1}$ figure-1d. The IR spectra of physical mixtures of baclofen with PEG 6000 demonstrated the characteristic absorption bands for aromatic C-C stretch at $1502.44 \mathrm{~cm}^{-1}$, aromatic $\mathrm{C}-\mathrm{H}$ stretch at $3055.03 \mathrm{~cm}^{-1}, \mathrm{C}-\mathrm{Cl}$ stretch at $844.76 \mathrm{~cm}^{-1}, \mathrm{C}-\mathrm{O}$ stretch at $1238.21 \mathrm{~cm}^{-1}, \mathrm{O}-\mathrm{H}$ bending at 1390.58 $\mathrm{cm}^{-1}, \mathrm{C}-\mathrm{H}$ alkane stretch at $2972.10 \mathrm{~cm}^{-1}, \mathrm{C}-\mathrm{O}-\mathrm{C}$ ether stretch at $1124.82 \mathrm{~cm}^{-1}$ figure-1e. The IR spectra of physical mixtures of baclofen with poloxamer 188 demonstrated the characteristic absorption bands for $\mathrm{C}-\mathrm{Cl}$ stretch at $734.83 \mathrm{~cm}^{-1}$, aromatic $\mathrm{C}-\mathrm{H}$ stretch at $3047.32 \mathrm{~cm}^{-1}, \mathrm{C}-\mathrm{O}$ stretch at $1236.29 \mathrm{~cm}^{-1}, \mathrm{O}-\mathrm{H}$ stretch at $3639.43 \mathrm{~cm}^{-1}, \mathrm{C}-\mathrm{H}$ alkane stretch at $2887.24 \mathrm{~cm}^{-1}$ figure-1f.

The IR spectra of solid dispersion of baclofen with PEG 6000 has showed the characteristic absorption bands for $\mathrm{C}-\mathrm{Cl}$ stretch at $804.26 \mathrm{~cm}^{-1}$, aromatic $\mathrm{C}-\mathrm{C}$ stretch at $1502.44 \mathrm{~cm}^{-1}$, aromatic $\mathrm{C}-\mathrm{H}$ stretch at $3047.90 \mathrm{~cm}^{-1}, \mathrm{C}-\mathrm{O}$ stretch at $1236.29 \mathrm{~cm}^{-1}, \mathrm{O}-\mathrm{H}$ bending at $1448.44 \mathrm{~cm}^{-1}$ figure-1g. The IR spectra of solid dispersion of baclofen with poloxamer 188 showed that the characteristic absorption bands for $\mathrm{C}-\mathrm{Cl}$ stretch at $833.19 \mathrm{~cm}^{-1}$, aromatic C-C stretch at $1531.37 \mathrm{~cm}^{-1}$, aromatic $\mathrm{C}-\mathrm{H}$ stretch at $3045.39 \mathrm{~cm}^{-1}$, C-O stretch at $1242.07 \mathrm{~cm}^{-1}, \mathrm{O}-\mathrm{H}$ bending at $1396.07 \mathrm{~cm}^{-1}$ figure- $1 \mathrm{~h}$. The IR spectra of solid dispersion of baclofen with PEG 6000 and HPMC K4M showed the characteristic absorption bands for $\mathrm{C}-\mathrm{Cl}$ stretch at $831.26 \mathrm{~cm}^{-1}$, aromatic $\mathrm{C}-\mathrm{C}$ stretch at 1521.73 $\mathrm{cm}^{-1}$, aromatic C-H stretch at $3068.53 \mathrm{~cm}^{-1}, \mathrm{C}-\mathrm{O}$ stretch at $1240.14 \mathrm{~cm}^{-1}, \mathrm{O}-\mathrm{H}$ bending at 1394.44 $\mathrm{cm}^{-1}$ figure-1i. The spectra of solid dispersion of baclofen with PEG 6000 and HPMC K100 showed the characteristic absorption bands for $\mathrm{C}-\mathrm{Cl}$ stretch at $833.19 \mathrm{~cm}^{-1}$, aromatic $\mathrm{C}-\mathrm{C}$ stretch at 1539.09 
$\mathrm{cm}^{-1}$, aromatic C-H stretch at $3085.89 \mathrm{~cm}^{-1}, \mathrm{C}-\mathrm{O}$ stretch at $1245.93 \mathrm{~cm}^{-1}, \mathrm{O}-\mathrm{H}$ bending at 1396.37 $\mathrm{cm}^{-1}$ figure-1j. The IR spectra of solid dispersion of baclofen with poloxamer 188 and HPMC K4M has demonstrated the characteristic absorption bands for $\mathrm{C}-\mathrm{Cl}$ stretch at $811.98 \mathrm{~cm}^{-1}$, aromatic CC stretch at $1502.44 \mathrm{~cm}^{-1}$, aromatic C-H stretch at $3093.61 \mathrm{~cm}^{-1}, \mathrm{C}-\mathrm{O}$ stretch at $1232.43 \mathrm{~cm}^{-1}, \mathrm{O}-\mathrm{H}$ bending at $1448.44 \mathrm{~cm}^{-1}$ figure-1k. The IR spectra of solid dispersion of baclofen with poloxamer 188 and HPMC K100 has demonstrated the characteristic absorption bands for $\mathrm{C}-\mathrm{Cl}$ stretch at $810.05 \mathrm{~cm}^{-1}$, aromatic C-C stretch at $1448.44 \mathrm{~cm}^{-1}$, aromatic C-H stretch at $3056.96 \mathrm{~cm}^{-1}, \mathrm{C}-\mathrm{O}$ stretch at $1261.36 \mathrm{~cm}^{-1}$, O-H bending at $1413.72 \mathrm{~cm}^{-1}$ figure-11. From the above studies it can be concluded that the peaks obtained in the spectra of each sample correlates with the peaks of drug spectrum. Therefore, it has been observed that the absence of chemical and physical interaction between baclofen and the carriers used. 


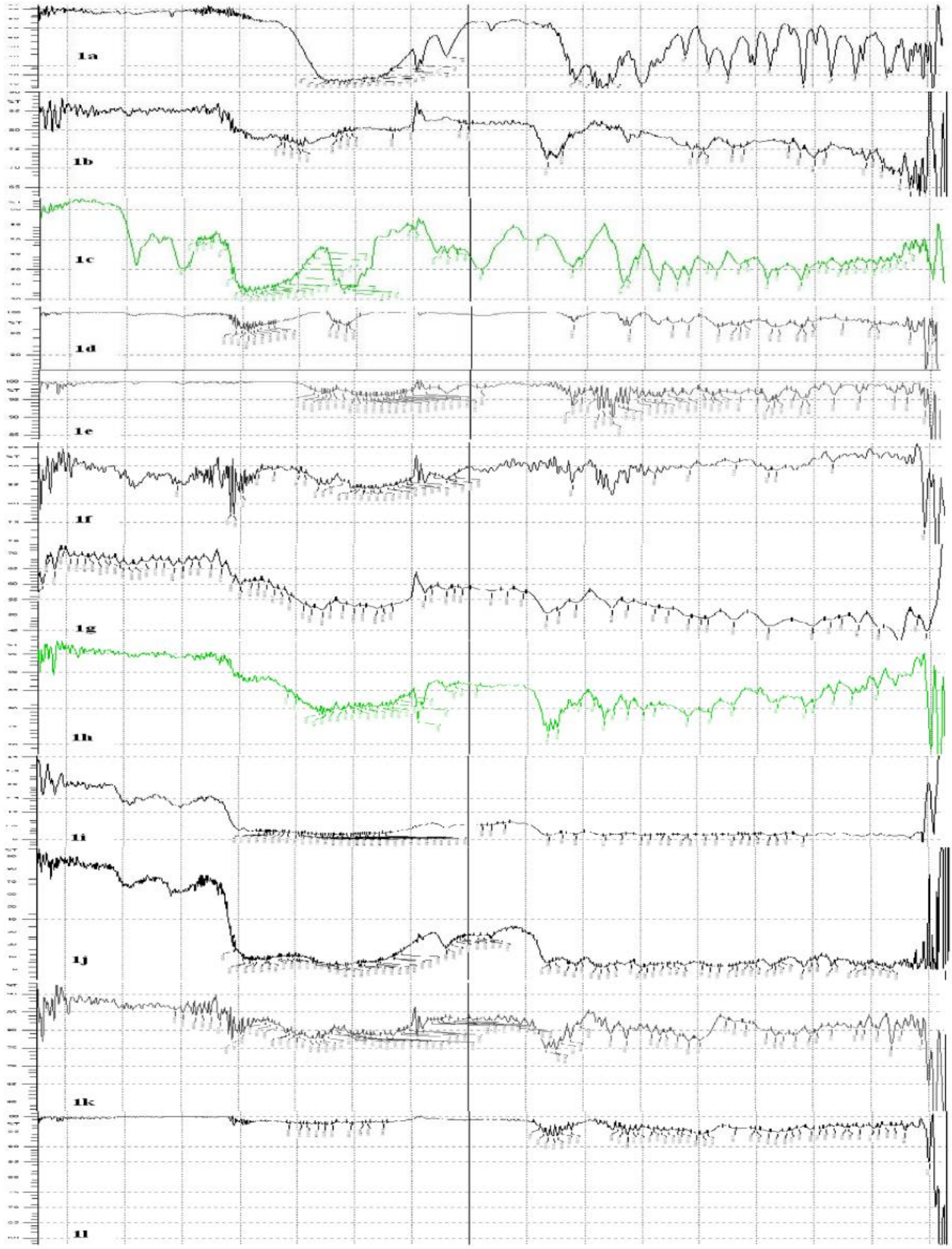

Fig.1. FT-IR spectra of: 1a - Baclofen, 1b - Carbopol 934P, 1c - PEG 6000, 1d - Poloxamer 188, 1e - Physical mixtures of baclofen with PEG 6000, 1f - Physical mixtures of baclofen with 
poloxamer 188, $1 \mathrm{~g}$ - Solid dispersion of baclofen with PEG 6000, 1h - Solid dispersion of baclofen with poloxamer 188, $1 \mathrm{i}$ - Solid dispersion of baclofen with PEG 6000 and HPMC K4M, $1 \mathrm{j}$ - Solid dispersion of baclofen with PEG 6000 and HPMC K100, 1k - Solid dispersion of baclofen with poloxamer 188 and HPMC K4M, 11 - Solid dispersion of baclofen with poloxamer 188 and HPMC K100.

\subsection{Differential scanning calorimetry studies}

The DSC analysis of pure drug, polymers and the physical mixture were carried out to evaluate possibility of interaction between drug and polymer. The DSC thermogram of pure drug baclofen showed a characteristic endothermic peak at $214.16^{\circ} \mathrm{C}$ as in figure $2 \mathrm{a}$ which corresponds to the melting point of baclofen. The DSC thermogram of PEG 6000 showed a characteristic endothermic peak at $65.75^{\circ} \mathrm{C}$ as in figure $2 \mathrm{~b}$ and thermogram of poloxamer 188 showed a sharp endothermic peak $55.56^{\circ} \mathrm{C}$ (figure $2 \mathrm{c}$ ) that corresponds to their respective melting points. The thermogram of carbolpol 934P showed a characteristic endothermic peak at $230.70^{\circ} \mathrm{C}$ (figure $2 \mathrm{~d}$ ). Similar endothermic peaks at $206.74^{\circ} \mathrm{C}$ and $207.80^{\circ} \mathrm{C}$ (figures-2e, 2f) were observed in the solid dispersions samples. It was observed that there was a slight variation in the melting point in the solid dispersion product as evident from figure $2 \mathrm{e}$ and $2 \mathrm{f}$. The observed peaks were not sharp and it forms a blant curve type of peak. This could be attributed to the conversion of amorphous form of drug from its original crystalline state. This proved the formation of amorphous solid dispersion product and this study confirmed that there was no interaction between the drug and the polymer. 

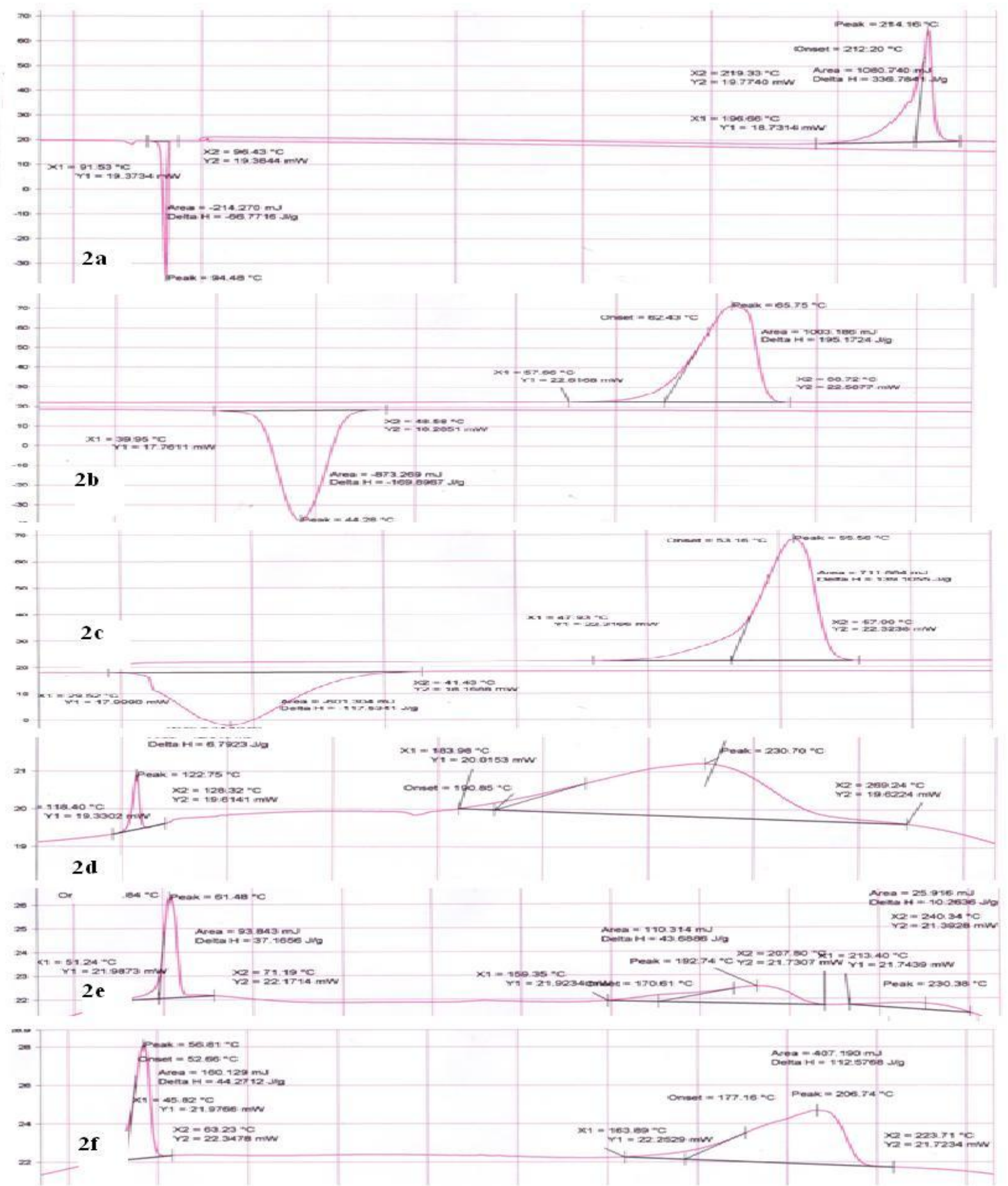

Fig. 2. DSC thermograms of : 2a-Baclofen, 2b- PEG 6000, 2c- Poloxamer 188, 2d-Carbolpol 934P, 2e- Solid dispersion of baclofen with PEG 6000, 2f- Solid dispersion of baclofen with poloxamer 188. 


\subsection{XRD studies}

The XRD results were in good agreement with the thermal analysis data. X-ray diffraction patterns in figure $3 \mathrm{a}$ revealed that pure baclofen was clearly in crystalline state as it showed sharp distinct peaks notably at $2 \theta$ diffraction angles of $17.5^{\circ}, 18^{\circ}, 19^{\circ}, 21.5^{\circ}, 23^{\circ}, 23.5^{\circ}, 25^{\circ}, 26^{\circ}, 28^{\circ}, 29^{\circ}, 31^{\circ}$ and $39^{\circ}$. PEG 6000 was in crystalline state as it showed sharp distinct peaks at $2 \theta$ diffraction angles of $19^{\circ}$ and $23.5^{\circ}$ as shown in figure $3 \mathrm{~b}$. The X-ray diffraction patterns of carbopol 934P shown in figure $3 \mathrm{c}$ did not show any characteristic peaks, indicating that it is amorphous in nature. The Xray diffraction patterns of Poloxamer 188 shown in figure $3 \mathrm{~d}$ showed sharp distinct peaks notably at $2 \theta$ diffraction angles of $19^{\circ}, 23.5^{\circ}$ indicating that it is crystalline in nature. X-ray diffraction patterns of solid dispersions prepared with PEG 6000 and Poloxamer 188 as shown in figures 3e and $3 \mathrm{f}$ showed decreased intensity of peaks. The XRD pattern of solid dispersion of baclofen prepared with Poloxamer 188 and PEG 6000 showed diffraction angles similar to that of pure baclofen but the intensity of crystallinity was reduced as evidenced from the peaks. This reduced intensity could be due to the conversion of drug into amorphous form partially and there by this XRD results indicated the absence of significant interactions between drug excipients in the preparation of SD granules. 


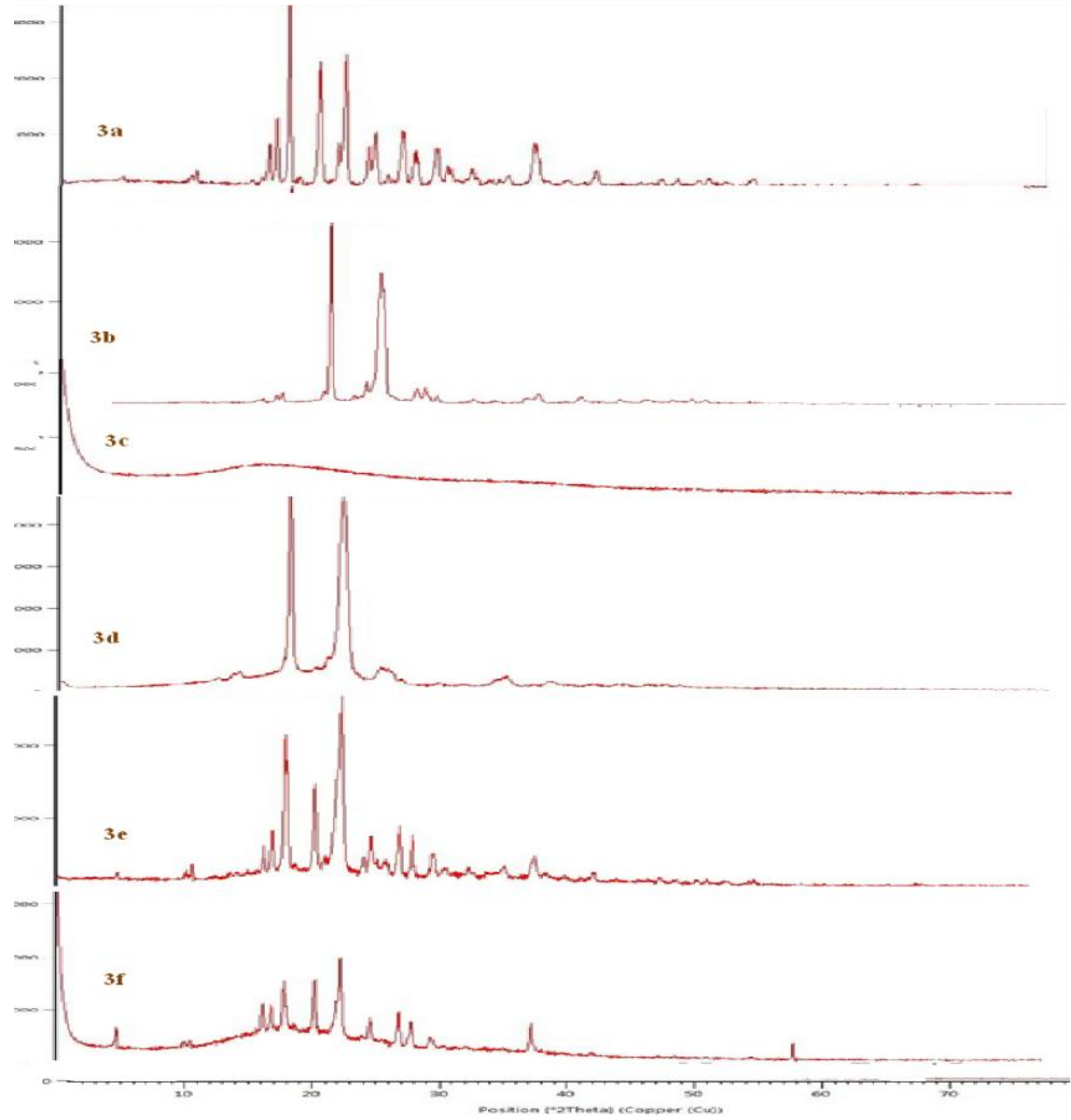

Fig.3. X-ray diffractograms of: 3a-Baclofen, 3b- PEG 6000, 3c- Carbolpol 934P, 3d- Poloxamer 188, 3e- Solid dispersion of baclofen with PEG 6000, 3f- Solid dispersion of baclofen with poloxamer 188 


\subsection{Formulation and evaluation of SR tablets containing solid dispersions.}

Based on the preliminary trials two formulations of solid dispersions were selected for formulation of sustained release tablets based on their increased solubility and dissolution. These solid dispersions were converted into sustained release tablets by direct compression method using HPMC K4M and HPMC K100 as release retarding agents. Dicalcium phosphate used as diluent and magnesium stearate was selected as lubricant, carbopol 934P is used as adsorbent, PEG 6000 and Poloxamer 188 are used to enhance the dissolution properties of poorly soluble compound like baclofen by formulating solid dispersion.

\subsection{Pre-compression parameters}

\section{Flow properties}

The pre-compression parameters for the all 12 formulations were carried out and the results were shown in the table- 2 . The bulk density of all 12 formulations ranged between 0.513 to $0.652 \mathrm{~g} / \mathrm{ml}$ and tapped density ranged from 0.605 to $0.835 \mathrm{~g} / \mathrm{ml}$. Hausner's ratio with values less than 1.35 indicates good flow property. All the formulations showed values less than 1.35 thereby confirming the free flowing nature of the prepared granules. The Carr's index value was between the range 8 to $26 \%$ which confirmed that all 12 formulations showing excellent flow properties and good compressibility. 
Table 2. Pre-compression parameters of prepared SR solid dispersion granules

\begin{tabular}{|c|c|c|c|c|}
\hline $\begin{array}{c}\text { Formulation } \\
\text { code }\end{array}$ & $\begin{array}{c}\text { Bulk density* } \\
(\mathrm{g} / \mathrm{ml})\end{array}$ & $\begin{array}{c}\text { Tapped density* } \\
(\mathrm{g} / \mathrm{ml})\end{array}$ & Hausner's ratio* & $\begin{array}{c}\text { Carr's index* } \\
(\%)\end{array}$ \\
\hline $\mathrm{A}_{1} \mathrm{~F}_{1}$ & $0.652 \pm 0.0015$ & $0.835 \pm 0.0030$ & $1.275 \pm 0.0030$ & $21.65 \pm 0.03$ \\
\hline $\mathrm{A}_{1} \mathrm{~F}_{2}$ & $0.600 \pm 0.0010$ & $0.806 \pm 0.0020$ & $1.335 \pm 0.0025$ & $25.18 \pm 0.06$ \\
\hline $\mathrm{A}_{1} \mathrm{~F}_{3}$ & $0.599 \pm 0.0010$ & $0.775 \pm 0.0020$ & $1.353 \pm 0.0200$ & $23.36 \pm 0.04$ \\
\hline $\mathrm{A}_{2} \mathrm{~F}_{1}$ & $0.583 \pm 0.0015$ & $0.675 \pm 0.0020$ & $1.155 \pm 0.0025$ & $13.46 \pm 0.04$ \\
\hline $\mathrm{A}_{2} \mathrm{~F}_{2}$ & $0.572 \pm 0.0015$ & $0.686 \pm 0.0020$ & $1.194 \pm 0.0030$ & $16.17 \pm 0.06$ \\
\hline $\mathrm{A}_{2} \mathrm{~F}_{3}$ & $0.553 \pm 0.0015$ & $0.605 \pm 0.0020$ & $1.095 \pm 0.0025$ & $8.38 \pm 0.04$ \\
\hline $\mathrm{B}_{1} \mathrm{~F}_{1}$ & $0.582 \pm 0.0015$ & $0.705 \pm 0.0025$ & $1.23 \pm 0.0200$ & $17.18 \pm 0.04$ \\
\hline $\mathrm{B}_{1} \mathrm{~F}_{2}$ & $0.513 \pm 0.0015$ & $0.627 \pm 0.0020$ & $1.215 \pm 0.0025$ & $17.74 \pm 0.04$ \\
\hline $\mathrm{B}_{1} \mathrm{~F}_{3}$ & $0.516 \pm 0.0010$ & $0.656 \pm 0.0030$ & $1.274 \pm 0.0030$ & $21.57 \pm 0.04$ \\
\hline $\mathrm{B}_{2} \mathrm{~F}_{1}$ & $0.584 \pm 0.0015$ & $0.735 \pm 0.0030$ & $1.255 \pm 0.0020$ & $20.55 \pm 0.04$ \\
\hline $\mathrm{B}_{2} \mathrm{~F}_{2}$ & $0.544 \pm 0.0015$ & $0.704 \pm 0.0030$ & $1.296 \pm 0.0025$ & $22.85 \pm 0.04$ \\
\hline $\mathrm{B}_{2} \mathrm{~F}_{3}$ & $0.513 \pm 0.0005$ & $0.625 \pm 0.0020$ & $1.215 \pm 0.0025$ & $17.79 \pm 0.05$ \\
\hline & $*$ Average of three determinations & \\
\hline
\end{tabular}

\subsection{Post-compression parameters}

\section{Weight variation test}

The weights of all tablet formulations ranged between 300 to $301 \mathrm{mg}$ (Table-3). As the weight of tablets was $300 \mathrm{mg}$, the acceptable weight variation range was between 285 to $315 \mathrm{mg}( \pm 5 \%)$. It was observed that all the tablet formulations were within the pharmacopoeial limits.

\section{Hardness}

The hardness of all formulations was determined and the results were shown in the table- 3 . The values of hardness were found to be in the range of 4.66 to $5.6 \mathrm{~kg} / \mathrm{cm}^{2}$.

\section{Friability}

The percentage friability of all the formulations was found to be not more than $0.7 \%$, which is well within the limit of $<1 \%$. The results of friability indicated that the tablets were mechanically stable. 


\section{Thickness}

The mean thickness of the SR tablets was determined and the values were found to be in the range of 4 to $4.17 \mathrm{~mm}$.

Table 3. Post compression parameters for prepared tablets

\begin{tabular}{|c|c|c|c|c|c|}
\hline $\begin{array}{c}\text { Formulation } \\
\text { code }\end{array}$ & $\begin{array}{c}\text { Weight } \\
\text { variation* } \\
(\mathrm{mg})\end{array}$ & $\begin{array}{c}\text { Friability* } \\
(\%)\end{array}$ & $\begin{array}{c}\text { Hardness* } \\
\left(\mathrm{kg} / \mathrm{cm}^{2}\right)\end{array}$ & $\begin{array}{c}\text { Thickness* } \\
(\mathrm{mm})\end{array}$ & $\begin{array}{c}\text { Percentage } \\
\text { drug content* }\end{array}$ \\
\hline $\mathrm{A}_{1} \mathrm{~F}_{1}$ & $300.5 \pm 3.94$ & $0.663 \pm 0.0041$ & $5.4 \pm 0.15$ & $4.13 \pm 0.025$ & $98.18 \pm 0.98$ \\
\hline $\mathrm{A}_{1} \mathrm{~F}_{2}$ & $301 \pm 3.07$ & $0.664 \pm 0.0045$ & $5.53 \pm 0.15$ & $4.17 \pm 0.025$ & $98.90 \pm 0.45$ \\
\hline $\mathrm{A}_{1} \mathrm{~F}_{3}$ & $301 \pm 5.52$ & $0.335 \pm 0.0045$ & $5.13 \pm 0.15$ & $4.08 \pm 0.076$ & $97.58 \pm 0.09$ \\
\hline $\mathrm{A}_{2} \mathrm{~F}_{1}$ & $300 \pm 3.24$ & $0.338 \pm 0.0050$ & $4.9 \pm 0.2$ & $4.01 \pm 0.032$ & $98.11 \pm 0.40$ \\
\hline $\mathrm{A}_{2} \mathrm{~F}_{2}$ & $300.5 \pm 3.94$ & $0.336 \pm 0.0060$ & $5.6 \pm 0.3$ & $4.07 \pm 0.037$ & $99.42 \pm 0.92$ \\
\hline $\mathrm{A}_{2} \mathrm{~F}_{3}$ & $301 \pm 3.07$ & $0.337 \pm 0.0055$ & $4.7 \pm 0.25$ & $4.05 \pm 0.07$ & $96.79 \pm 0.34$ \\
\hline $\mathrm{B}_{1} \mathrm{~F}_{1}$ & $300.5 \pm 3.94$ & $0.172 \pm 0.0060$ & $5.26 \pm 0.37$ & $4.06 \pm 0.030$ & $99.09 \pm 1.39$ \\
\hline $\mathrm{B}_{1} \mathrm{~F}_{2}$ & $300.5 \pm 2.23$ & $0.337 \pm 0.0050$ & $5.5 \pm 0.26$ & $4.05 \pm 0.05$ & $99.04 \pm 1.03$ \\
\hline $\mathrm{B}_{1} \mathrm{~F}_{3}$ & $300.5 \pm 3.94$ & $0.172 \pm 0.0060$ & $4.7 \pm 0.2$ & $4.03 \pm 0.05$ & $97.75 \pm 0.55$ \\
\hline $\mathrm{B}_{2} \mathrm{~F}_{1}$ & $300.5 \pm 2.32$ & $0.172 \pm 0.0060$ & $4.76 \pm 0.25$ & $4.04 \pm 0.05$ & $98.03 \pm 0.55$ \\
\hline $\mathrm{B}_{2} \mathrm{~F}_{2}$ & $300.5 \pm 3.94$ & $0.172 \pm 0.0060$ & $5.53 \pm 0.25$ & $4.06 \pm 0.06$ & $98.5 \pm 0.7$ \\
\hline $\mathrm{B}_{2} \mathrm{~F}_{3}$ & $300.5 \pm 2.23$ & $0.172 \pm 0.0060$ & $4.66 \pm 0.15$ & $4.15 \pm 0.05$ & $98.75 \pm 0.88$ \\
\hline
\end{tabular}

*Average of three determinations 


\subsection{Drug content estimation}

The drug content uniformity was performed for all the formulations and the results were shown in Table-3. The uniformity of drug distribution within the batch tablets was confirmed by the assay values of 96.7 to $99.4 \%$ for all the formulations.

\section{In-vitro drug release studies}

In-vitro dissolution studies were performed for all the formulated tablets using USP dissolution test apparatus Type II employing rotating paddle method at $50 \mathrm{rpm}$ using $900 \mathrm{ml}$ of pH 1.2 solution for first two hours and $\mathrm{pH} 6.8$ phosphate buffer for next hours until 100\% drug release and the temperature of dissolution medium was maintained at $37 \pm 0.5^{\circ} \mathrm{C}$. The results of in-vitro drug release profiles are shown in figure 4-7. Solid dispersions of baclofen with Poloxamer 188 in the ratio 1:1 released drug completely within $30 \mathrm{~min}$ where as solid dispersions in the ratio 1:0.5 showed complete drug release at the end of $45 \mathrm{~min}$ and ratio 1:2 showed complete drug release at the end of $40 \mathrm{~min}$. The solid dispersions of baclofen with PEG 6000 in the ratio 1:1 released drug completely within $30 \mathrm{~min}$ where as solid dispersions in the ratio 1:0.5 showed complete drug release at the end of $50 \mathrm{~min}$ and ratio 1:2 showed complete drug release at the end of $35 \mathrm{~min}$. Dissolution studies of the solid dispersion granules in the weight ratio of drug, carrier and adsorbent( $1: 1: 1)$ showed $100 \%$ drug release within 30 minutes where as the other ratios of drug, carrier and adsorbent took more than 40 minutes for $100 \%$ drug release. The solid dispersion granules composed of baclofen with Poloxamer 188 and baclofen with PEG 6000 showed improved drug dissolution. The hydrophilic properties of the carriers probably led to the improved dissolution by increased wetting and reduced interfacial tension between drug and the dissolution medium. Therefore dissolution enhancement is a function of solid dispersion. Formulation $\mathrm{B}_{1} \mathrm{~F}_{1}$ showed complete drug release within 7 hours, formulations $A_{1} F_{3}, B_{1} F_{2}, B_{1} F_{3}, B_{2} F_{1}$ showed complete drug release within 8 hours, formulations $\mathrm{A}_{1} \mathrm{~F}_{1}, \mathrm{~A}_{1} \mathrm{~F}_{2}, \mathrm{~A}_{2} \mathrm{~F}_{3}, \mathrm{~B}_{2} \mathrm{~F}_{3}$ showed complete drug release within 9 hours, whereas other formulations $\mathrm{A}_{2} \mathrm{~F}_{1}, \mathrm{~A}_{2} \mathrm{~F}_{2}, \mathrm{~B}_{2} \mathrm{~F}_{2}$ exhibited release up to 10 hours. The studies indicated the drug release retarding efficiency with the polymer concentration of the formulations. 


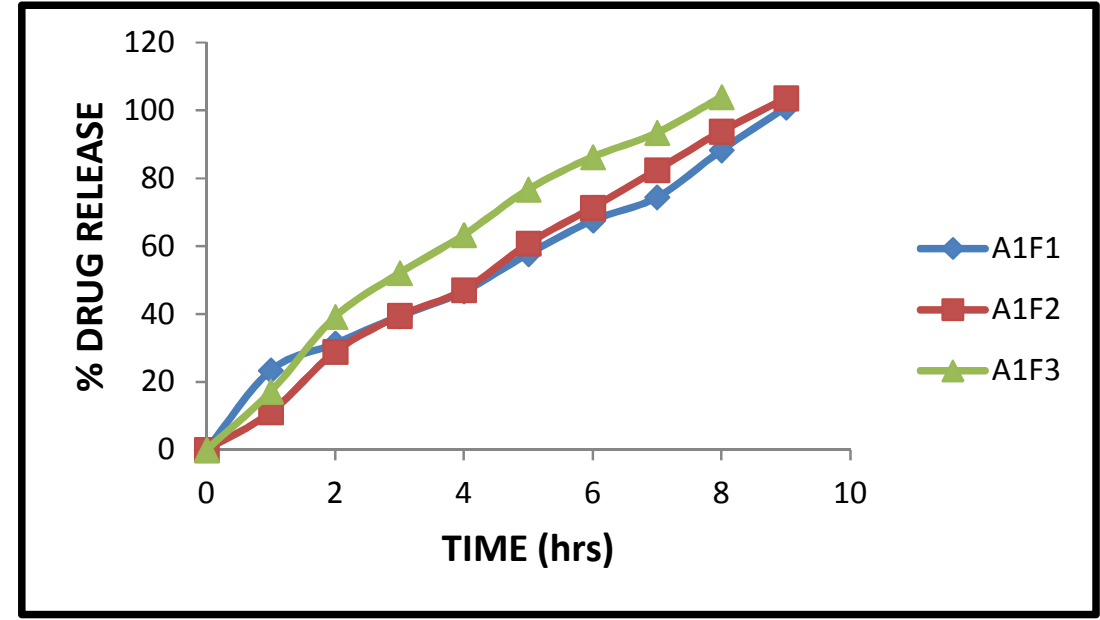

Fig.4. In-Vitro drug release profile of formulations $\mathrm{A}_{1} \mathrm{~F}_{1}$ to $\mathrm{A}_{1} \mathrm{~F}_{3}$

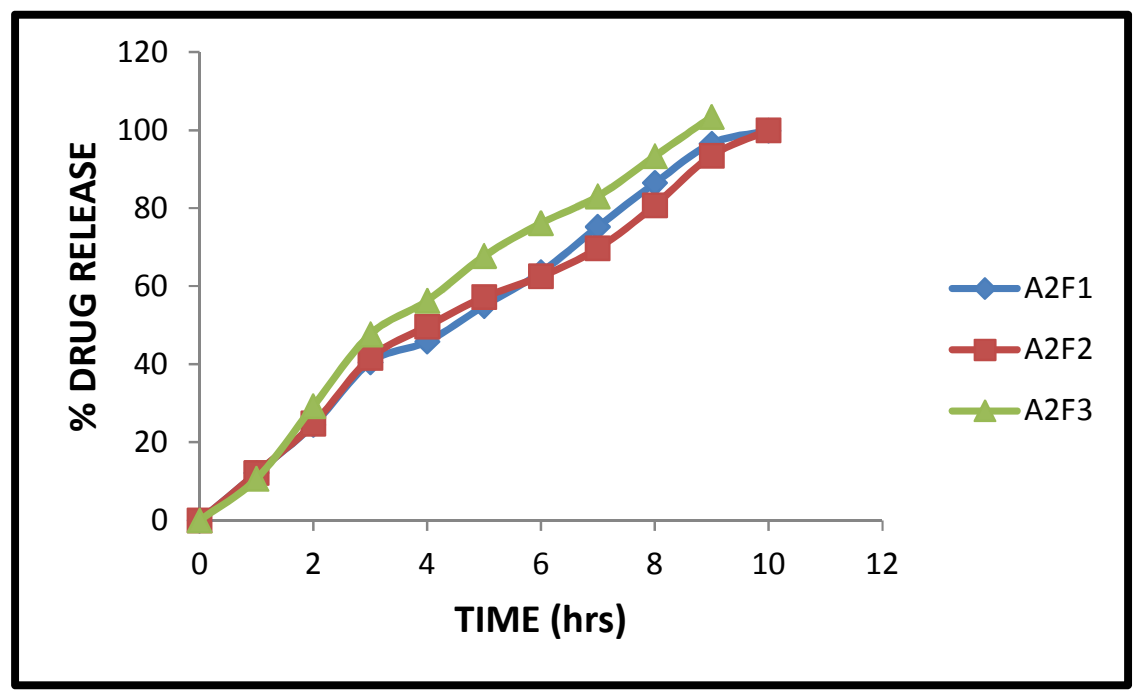

Fig.5. In-Vitro drug release profile of formulations $A 2 \mathrm{~F}_{1}$ to $\mathrm{A}_{2} \mathrm{~F}_{3}$ 


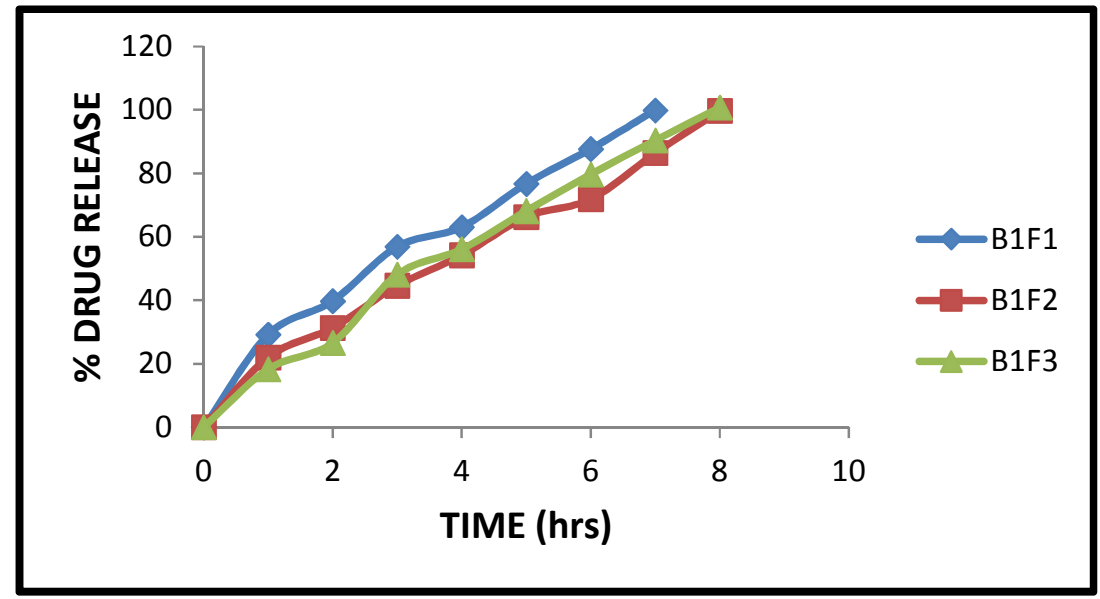

Fig.6. In-Vitro drug release profile of formulations $\mathrm{B}_{1} \mathrm{~F}_{1}$ to $\mathrm{B}_{1} \mathrm{~F}_{3}$

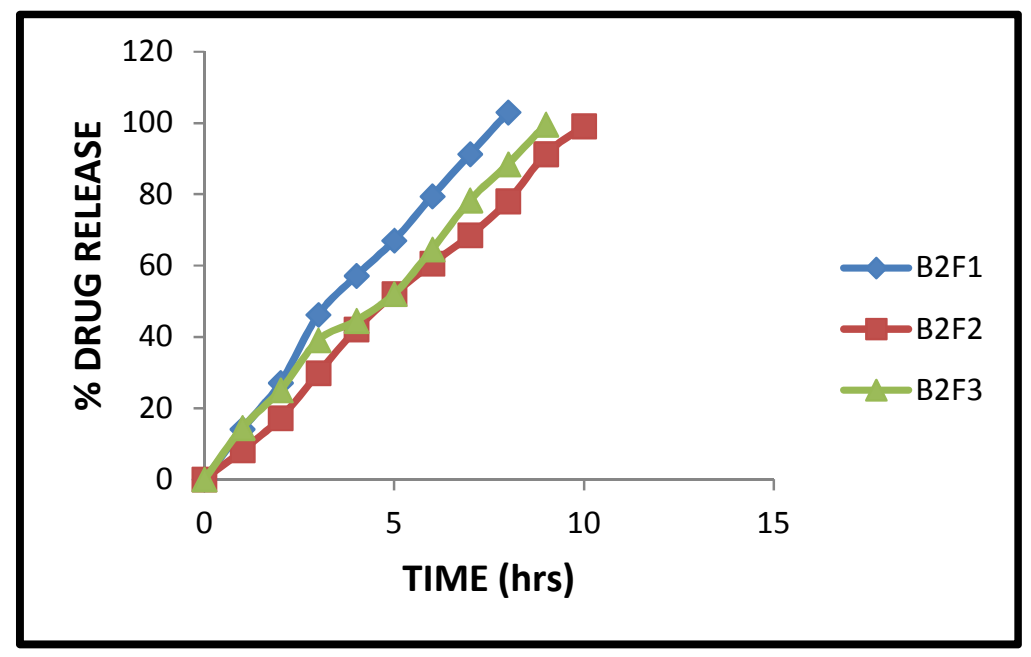

Fig.7. In-Vitro drug release profile of formulations $\mathrm{B}_{2} \mathrm{~F}_{1}$ to $\mathrm{B}_{2} \mathrm{~F}_{3}$

In-vitro drug release mechanism The drug release studies were fitted to various kinetic models like zero-order, First order, Higuchi, Korsemeyer Peppas and Hixon-Crowell model using PCP Disso V3 to predict the drug release mechanism. Models with highest correlation coefficient were judged to be most appropriate model for dissolution data. The drug release data when fitted into various kinetic equations, showed zero-order release pattern for all formulations except $A_{1} F_{3}$ 
showed hixon-Crowell with $\mathrm{R}$ value of $0.889, \mathrm{~B}_{1} \mathrm{~F}_{1}$ showed first order release with $\mathrm{R}$ value of 0.799 respectively. The drug release kinetics of all the formulations was shown in table 4 .

Table 4. Data for in-vitro drug release kinetics of the prepared sustained release tablet formulations

\begin{tabular}{|c|c|c|c|c|c|c|c|c|c|c|c|}
\hline \multirow{2}{*}{$\begin{array}{c}\text { Formulation } \\
\text { code }\end{array}$} & \multicolumn{2}{|c|}{ Zero order } & \multicolumn{2}{|c|}{ First order } & \multicolumn{2}{|c|}{ Matrix } & \multicolumn{2}{|c|}{$\begin{array}{l}\text { Hixon - } \\
\text { Crowell }\end{array}$} & \multicolumn{3}{|c|}{ Korsemeyer-Peppas } \\
\cline { 2 - 13 } & $\mathrm{R}$ & $\mathrm{K}$ & $\mathrm{R}$ & $\mathrm{K}$ & $\mathrm{R}$ & $\mathrm{K}$ & $\mathrm{R}$ & $\mathrm{K}$ & $\mathrm{R}$ & $\mathrm{K}$ & $\mathrm{n}$ \\
\hline $\mathrm{A}_{1} \mathrm{~F}_{1}$ & $\mathbf{0 . 8 6 3}$ & 6.959 & 0.838 & 0.105 & 0.782 & 17.08 & 0.854 & 0.03 & 0.521 & 12.63 & 0.566 \\
\hline $\mathrm{A}_{1} \mathrm{~F}_{2}$ & $\mathbf{0 . 9 3 7}$ & 7.940 & 0.885 & 0.131 & 0.830 & 19.26 & 0.909 & 0.03 & 0.822 & 7.48 & 0.962 \\
\hline $\mathrm{A}_{1} \mathrm{~F}_{3}$ & 0.878 & 8.022 & 0.886 & 0.116 & 0.845 & 18.92 & $\mathbf{0 . 8 8 9}$ & 0.03 & 0.684 & 13.92 & 0.628 \\
\hline $\mathrm{A}_{2} \mathrm{~F}_{1}$ & $\mathbf{0 . 9 5 7}$ & 7.532 & 0.910 & 0.126 & 0.849 & 19.23 & 0.931 & 0.03 & 0.811 & 6.87 & 0.981 \\
\hline $\mathrm{A}_{2} \mathrm{~F}_{2}$ & $\mathbf{0 . 9 7 4}$ & 7.306 & 0.915 & 0.117 & 0.886 & 18.82 & 0.942 & 0.03 & 0.937 & 9.24 & 0.849 \\
\hline $\mathrm{A}_{2} \mathrm{~F}_{3}$ & $\mathbf{0 . 9 7 4}$ & 8.224 & 0.934 & 0.131 & 0.898 & 20.24 & 0.955 & 0.03 & 0.934 & 9.13 & 0.924 \\
\hline $\mathrm{B}_{1} \mathrm{~F}_{1}$ & 0.793 & 6.443 & $\mathbf{0 . 7 9 9}$ & 0.10 & 0.780 & 17.85 & 0.799 & 0.02 & 0.417 & 20.96 & 0.326 \\
\hline $\mathrm{B}_{1} \mathrm{~F}_{2}$ & $\mathbf{0 . 8 9 7}$ & 7.418 & 0.870 & 0.12 & 0.832 & 20.98 & 0.883 & 0.03 & 0.640 & 12.82 & 0.613 \\
\hline $\mathrm{B}_{1} \mathrm{~F}_{3}$ & $\mathbf{0 . 9 7 3}$ & 9.179 & 0.934 & 0.16 & 0.908 & 26.12 & 0.951 & 0.04 & 0.918 & 11.52 & 0.817 \\
\hline $\mathrm{B}_{2} \mathrm{~F}_{1}$ & $\mathbf{0 . 9 7 0}$ & 9.527 & 0.924 & 0.17 & 0.898 & 26.88 & 0.945 & 0.04 & 0.933 & 8.678 & 0.979 \\
\hline $\mathrm{B}_{2} \mathrm{~F}_{2}$ & $\mathbf{0 . 9 8 1}$ & 9.072 & 0.916 & 0.18 & 0.898 & 28.85 & 0.947 & 0.04 & 0.970 & 2.848 & 1.482 \\
\hline $\mathrm{B}_{2} \mathrm{~F}_{3}$ & $\mathbf{0 . 9 4 0}$ & 8.203 & 0.897 & 0.14 & 0.852 & 24.28 & 0.916 & 0.04 & 0.839 & 7.347 & 0.922 \\
\hline
\end{tabular}

\section{Stability studies}

The accelerated stability studies of baclofen SR tablets were performed as per the ICH guidelines to investigate whether the tablets are affected during storage conditions. The sample batch tablets from formulations $\mathrm{A}_{1} \mathrm{~F}_{2}, \mathrm{~A}_{2} \mathrm{~F}_{2}, \mathrm{~B}_{1} \mathrm{~F}_{2}$ and $\mathrm{B}_{2} \mathrm{~F}_{2}$ were kept at $40^{\circ} \mathrm{C} / 75 \%$ relative humidity for a period of 6 months. The physical appearance, hardness, drug content and dissolution rate were measured for formulations at the end of 2, 4 and 6 months. The results showed that there was no significant difference between the initial and aged baclofen SR tablets. The selected formulations $A_{1} F_{2}, A_{2} F_{2}$, 
$\mathrm{B}_{1} \mathrm{~F}_{2}$ and $\mathrm{B}_{2} \mathrm{~F}_{2}$ was physically and chemically stable for 6 months at accelerated stability conditions with minimal drug degradation at the end of the study.

\section{CONCLUSION}

The present study was aimed at an attempt to develop sustained release tablets containing solid dispersions of baclofen that require both solubilization and release modulation for therapeutic efficacy. A free flowing solid dispersion granule was obtained by surface adsorption of carriers on Carbopol 934P. Solid dispersion granules showed enhanced dissolution of baclofen. These results show that a combination of surface adsorption of solid dispersion and hydrophilic sustained release carriers is a promising approach to control the release rate of poorly water soluble drug like baclofen. The solid dispersion granules were directly compressed into tablets using hydrophilic polymers. The resulting sustained release tablets containing solid dispersion granules revealed linear release rate of Baclofen for $2 \mathrm{~h}$ in gastric fluid and followed by continuous release in intestinal fluid for up to $10 \mathrm{~h}$. Thus a stable, safe and effective sustained release tablet containing solid dispersion of baclofen can be formulated successfully.

\section{ACKNOWLEDGEMENTS}

The authors are thankful to Gokula Education Foundation, Bangalore for providing necessary facilities to carry out the research work and Indian Institute of Science, Bangalore for providing DSC and XRD facility.

\section{BIBILIOGRAPHY}

1. Vasconcelos T.F., Sarmento B., Costa P., Drug Dis. Today. 2007, 2, 1068-1075.

2. Sarkar B., Jain D., Agarwal A., Panwar A.S., Asian. J. Biomed. Pharm. Sci. 2011,1(2), 08-10.

3. Robinson J.R, Lee V.H. Controlled drug delivery fundamentals and applications. 2nd ed. New Delhi: CBS Publishers \& Distributors 2005, Vol 29, pp.375-420.

4. Jayaswal S.B., Subha P., Gupta V.K., Kumar V.M., The Eastern Pharm. 1994, 8, 159-161.

5. Patil S.A., Kuchekar B.S., Chabukswar A.R., Jagdale S.C., J Young Pharm. 2010, 2(2), 121129.

6. Prescribing information of Kemstro ${ }^{\mathrm{TM}}$ (Baclofen orally disintegrating tablets $10 \mathrm{mg}$ and $20 \mathrm{mg}$, Schwarz Pharma, USA) 30 $30^{\text {th }}$ October 2003. 
7. URL: http://en.wikipedia.org/wiki/Baclofen (Accessed on 05th Dec 2012)

8. URL: http://www.druglib.com (Accessed on November 2012)

9. Indian Pharmacopoeia. 6th ed. Ghaziabad. Published by Indian Pharmacopoeia commission 2010,2513

10. Hiroshi Y., Tetsuya O., Yoshio K., Katsutoshi O., Chem. Pharm. Bull. 1992, 40(6), 1592-1596.

11. Grzegorz G., Henning B., Werner W., Dissolution Tech. 2009,6, 7-13

12. ICH.Guidelines, Geneva: International conference on harmonization of technical requirements for registration of pharmaceuticals for human use; 2003, Accessed from: http://www.ich.org/Q1A (R2).

How to cite this article:

Janardhana K H, Deveswaran R, Bharath S, Basavaraj B V and Madhavan V. Development of sustained release tablets containing solid dispersions of baclofen. J. Fundam. Appl. Sci., 2013, 5(2), 220-239 